\title{
Refractive errors in albino children in Brazzaville
}

\author{
Nganga Ngabou Charles Géraud Fredy ${ }^{1,2 *}$, Makita Chantal ${ }^{1,2}$, Adiba Fene Samuel $^{3}$, Kambourou Judicaël ${ }^{1,4}$ and Onka Vissimy ${ }^{2,3}$ \\ ${ }^{1}$ University Marien Ngouabi, Brazzaville, Republic of Congo \\ ${ }^{2}$ Department of Ophthalmology, University Hospital of Brazzaville, Brazzaville, Republic of Congo \\ ${ }^{3}$ Clinic of Ophthalmology, Brazzaville, Republic of Congo \\ ${ }^{4}$ Department of Paediatrics, University Hospital of Brazzaville
}

\begin{abstract}
We evaluated refractive disorders in Albino children of Brazzaville and assessed their impact on the visual acuity of these children.

Patients and method: Our study was conducted at the University Hospital of Brazzaville in October 2018 as part of a special program of the Congolese Association of Albinos aimed at providing glasses free of charge to albino children. This was a cross-sectional study of 32 children with oculocutaneous albinism.

All children received a complete ophthalmological examination. Ametropia was measured by cycloplegic autorefraction performed approximately $45-60$ minutes after topical instillation of 3 drops of $1 \%$ cyclopentolate administered 5 minutes apart.

Results: All children had nystagmus, including 2 cases with strabismus (6.25\%). All children had astigmatism, 56.25\% of whom were hypermetropic. The mean corrected visual acuity in the better eye was $0.18+/-0.14$. The Mean uncorrected visual acuity in the better eye was $0.33+/-0.15$. The improvement in visual acuity after correction was statistically significant $\mathrm{P}=0.002$.
\end{abstract}

Conclusion: Albinism is associated with a variety of ocular anomalies including ametropia. Hypermetropic astigmatism was the most common refractive error identified in our series. Correction of this ametropia results in a statistically significant improvement in visual acuity.

\section{Introduction}

Albinism is a group of inherited disorders that are characterized by a reduction or absence of melanin pigment in tissues, in conjunction with ocular and visual pathway developmental abnormalities. The most characteristic manifestation of albinism is related to hypopigmentation in the visual system and/or the skin and teguments. This lack of production of melanin is associated with specific changes in the eye such as foveal hypoplasia and misrouting of optic fibres from the retina to the visual cortex [1].

These changes explain the low visual acuity that presents from birth. In addition, albinism is also associated with refractive disorders and reduced visual acuity [2].

The purpose of this study is to determine the refractive disorders in children of Albino Brazzaville and to appreciate their impact on the visual acuity of these children.

\section{Patients and methods}

\section{Patients}

Our study was conducted at the University Hospital of Brazzaville in October 2018 as part of a special program of the Congolese Association of Albinos aimed at providing glasses free of charge to albino children.

\section{Method}

This was a cross-sectional study of 32 children with oculocutaneous albinism.

All the selected children benefited from a complete ophthalmological examination. We used the best subjective corrected visual acuity and performed a detailed anatomical examination. Ametropia was measured by cycloplegic autorefraction performed approximately 45-60 minutes after topical instillation of 3 drops of $1 \%$ cyclopentolate administered 5 minutes apart [3].

A second assessment of visual acuity was performed the next day with optical correction.

We used the WHO classification of visual impairment [4-6] taking the best corrected vision in the better eye into account:

- Mild Visual Impairment: Visual acuity between 6/12 and 6/18 (between 0.5 and 0.3 )

- Moderate Visual Impairment: Visual acuity between 6/18 and 6/60 (between 0.3 and 0.1 )

- Severe visual impairment: Visual acuity between 6/60 and 3/60 (between 0.1 and 0.05)

- Blindness: Visual acuity worse than 3/60 (less than 0.05)

Since visual impairment and blindness are defined by considering the visual acuity of the better eye, our work was done separately on both eyes [5].

${ }^{*}$ Correspondence to: Nganga Ngabou Charles Géraud Fredy, Department of Ophthalmology, University Hospital of Brazzaville, Brazzaville, Republic of Congo, E-mail: fredygeraud@gmail.com

Key words: albinism, refraction errors, children

Received: February 25, 2019; Accepted: March 08, 2019; Published: March 11, 2019 


\section{Statistical analyses}

We used EPI INFO 7 for statistical analysis. Comparisons were carried out using Excel software by performing equality tests on paired predictions in one eye and on unpaired predictions in both eyes after comparing variances. The confidence interval was $95 \%$.

\section{Results}

Our study included 12 boys and 20 girls, a sex ratio of 0.6 . The average age was $12+/-3.06$ (5 to 15 years old). All children had nystagmus, including 2 cases with strabismus (6.25\%) (Table 1).

The mean uncorrected visual acuity in the better eye was $0.18+/$ 0.14 . The mean corrected visual acuity in the better eye was $0.33+/-0.15$. The improvement in corrected visual acuity was statistically significant $\mathrm{P}=0.002$. The mean corrected visual acuity of the contralateral eye $0.25+/-0.15$. The difference in the mean visual acuity of the two eyes was not statistically significant (Table 2).

\section{Discussion}

Our study included 12 boys and 20 girls, a sex ratio of 0.6 . Two Cameroonian studies Eballe and Aboubacar respectively found a sex ratio of 1.33 for men and 0.5 for women $[7,8]$. There is no gender predominance in albinism. these sex ratio variations, are probably random cases.

The average age in our study was $12+/-3.06$ years old, which is consistent with the fact that we only worked with on patients with 15 years of age or less. In the literature, however, the average age is generally low, 18 for Gargouri in Tunisia, 24 and 13 for Aboubacar and Ebana in Cameroon [8-10]. The latter had evoked a low life expectancy among African albinos, which had already been demonstrated by Madelain [11]. Nystagmus was present in $100 \%$ of patients according to the literature [7-10,12].

Two children had a strabismus or $6.25 \%$, this rate is a little lower than that findings in the literature. Khanal and Gargouri respectively found $16 \%$ and $13 \%$. Strabismus affected 2 children out of 32, or $6.25 \%$ of cases. Khanal noted $16 \%$ of strabismus, and Gargouri $13.88 \%[9,12]$.

Astigmatism was present in all patients. No patient had isolated spherical ametropia. Spherical ametropia associated with astigmatism

Table 1. Types of Ametropia

\begin{tabular}{|l|c|c|}
\hline Types of Ametropia & Number of cases & $\mathbf{\%}$ \\
\hline Hypermetropia & 0 & 0 \\
\hline Myopia & 0 & 0 \\
\hline Simple Hypermetropic Astigmatism & 8 & 25 \\
\hline Compound Hypermetropic Astigmatism & 10 & 31.25 \\
\hline Mixed Astigmatism & 2 & 6.25 \\
\hline Simple Myopic Astigmatism & 0 & 0 \\
\hline Composed Myopic Astigmatism & 12 & 37.5 \\
\hline Total & 32 & 100 \\
\hline
\end{tabular}

Table 2. Classification of patients based on visual acuity

\begin{tabular}{|l|c|c|c|}
\hline & $\begin{array}{c}\text { Uncorrected in } \\
\text { the better eye }\end{array}$ & $\begin{array}{c}\text { Corrected in the } \\
\text { better eye }\end{array}$ & $\begin{array}{c}\text { Corrected in the } \\
\text { contralateral eye }\end{array}$ \\
\hline No Visual Impairment & $0(0 \%)$ & $0(0 \%)$ & $0(0 \%)$ \\
\hline Minimal Visual Impairment & $8(25 \%)$ & $17(53.13 \%)$ & $10(31.25 \%)$ \\
\hline Moderate Visual Impairment & $8(25 \%)$ & $9(28.1 / 3 \%)$ & $12(37.5 \%)$ \\
\hline Severe Visual Impairment & $9(28.13 \%)$ & $4(12.5 \%)$ & $10(31.25 \%)$ \\
\hline Blindness & $7(21.88 \%)$ & $2(6.25 \%)$ & $0(0 \%)$ \\
\hline Total & $32(100 \%)$ & $32(100 \%)$ & $32(100 \%)$ \\
\hline
\end{tabular}

were dominated by farsightedness which accounted for $56.25 \%$ of cases, against myopia with $37.5 \%$ of cases. Gargouri also found $100 \%$ astigmatism, associated with $59 \%$ hyperopia and $41 \%$ myopia [9]. Ebana found $86.7 \%$ astigmatism, $9.53 \%$ myopia and $2.38 \%$ Hypermetropia [10].

The mean uncorrected visual acuity in the better eye was $0.18+/$ 0.14 and corrected visual acuity in the better eye was $0.33+/-0.15$ considering the best corrected vision. All patients had a visual acuity of $5 / 10$ or less. These results are better than Cameroonian studies with mean corrected visual acuity of $0.15+/-0.08$ for Eballe and $0.27+/-0.13$ for Aboubacar. This is explained by the fact that they included only albinos who presented themselves in consultation. In contrast, in our series we selected patients amongst an albino association.

The visual acuity improvement provided by the optical correction was clinically significant. This improvement was also found by authors in the literature $[7,13,14]$

Although the average corrected visual acuity was greater than the better eye compared to the contralateral eye, the difference was not clinically significant. This makes it possible to evoke a symmetric disorder a priori.

These results allow us to classify patients according to their level of vision:

- All patients had visual impairment,

- Without correction only $25 \%$ reached 0.3 of visual acuity,

- With correction $53 \%$ had a visual acuity between 0.3 and 0.5 ,

- Despite the correction, $18.75 \%$ of children still had severe visual impairment or remained blind.

Gargouri reports $36 \%$ of patients with visual acuity greater than $3 / 10$. Aboubacar also noted a maximum visual acuity at 0.5 [8.9].

\section{Conclusion}

Albinism is associated with a variety of ocular anomalies including ametropia. Hypermetropic astigmatism was the most common refractive error identified in our series. Correction of this ametropia results in a statistically significant improvement in visual acuity. Despite this improvement, patients remain visually impaired. The patients must be optically corrected and be informed of realistic expectations.

\section{References}

1. Aquaron R (2000) L’albinisme humain: aspects cliniques, génétiques, cellulaires, biochimiques et moléculaires. Med Trop 60: 331-341.

2. Wildsoet CF, Oswald PJ, Clark S (2000) Albinism: its implications for refractive development. Invest Ophthalmol Vis Sci 41: 1-7.

3. Sellami L, Le Lez ML, Santallier M, Thuault S, Madern F, et al. (2002) Étude de la réfraction sous cycloplégie: 2 gouttes de cyclopentolate versus 3 gouttes. JF Ophtalmol 25: 142 .

4. Blindness and vision impairment, World Health Organization 2018. www.who.int/ news-room/fact-sheets/detail/ blindness-and-visual-impairment.

5. Bourne RRA, Flaxman SR, Braithwaite T, Cicinelli MV, Das A (2017) Magnitude, temporal trends, and projections of the global prevalence of blindness and distance and near vision impairment: a systematic review and meta-analysis. Lancet Glob Health 5: 888-897. [Crossref]

6. Stevens G, White R, Flaxman SR (2013) Global prevalence of visual impairment and blindness: magnitude and temporal trends, 1990-2010. Ophthalmology 120: 2377 2384. [Crossref] 
7. Eballe AO, Mvogo CE, Noche C, Zoua MEA, Viola-Dohvoma A (2013) Refractive errors in Cameroonians diagnosed with complete oculocutaneous albinism. Clin Ophthalmol 7: 1491-1495. [Crossref]

8. Aboubakar H, Dohvoma V, Ebana Mvogo S, Malla G, Ndongo JA (2017) Les Caractéristiques du Nystagmus chez le Sujet Albinos Camerounais. Health Sci Dis 18 : 25-28.

9. Gargouri S, Kaibi L, Sakka M, Abib L, Sallami D, et al. (2017) La prise en charge optique des albinos en Tunisie. J I M Sfax 25: 40-44.

10. Mvogo CE, Bella-Hiag AL, Ellong A, Mbarga BM (1999) Les troubles visuels de l'albinos, étude hospitalière réalisée à l'Hôpital général de Douala. Cahiers santé 9: 89-91.
11. Madelain J, Turut P(1989) Albinisme: signes, diagnostic et traitement. L'ophtalmologie en question 1: 3-20.

12. Khanal S, Pokharel A, Kandel H (2016) Visual deficits in Nepalese patients with oculocutaneous albinism. J Optom 9: 102-109. [Crossref]

13. Rymer J, Choh V, Bharadwaj S, Padmanabhan V, Modilevsky L, et al. (2007) The albino chick as à model for studying ocular developmental anomalies, including refractive errors, associated with albinism. Exp Eye Res 85: 431-442. [Crossref]

14. Yahalom C, Tzur V, Blumenfeld A (2012) Refractive profile in oculo-cutaneous albinism and its correlation with final visual outcome. Br J Ophthalmol 96: 537-539. [Crossref]

Copyright: @2019 Fredy NNCG. This is an open-access article distributed under the terms of the Creative Commons Attribution License, which permits unrestricted use, distribution, and reproduction in any medium, provided the original author and source are credited. 